\title{
BENEFÍCIOS DA BIOMASSA DE BANANA VERDE Á SAÚDE HUMANA
}

\author{
Vânia Thais Silva Gomes' \\ Raimundo Nonato Silva Gomes ${ }^{2}$ \\ Maria Silva Gomes ${ }^{3}$ \\ Larissa Vanessa Machado Viana ${ }^{4}$ \\ Francileine Rodrigues da Conceição ${ }^{5}$ \\ Ed Luis Soares ${ }^{6}$ \\ Patrícia de Souza Genaro ${ }^{7}$
}

Resumo: A banana, principalmente quando verde e cozida, está inserida no grupo de alimentos funcionais do tipo prebióticos, por possuir amido resistente, no qual é de grande interesse da indústria alimentícia, por apresentar nutrientes importantes para a saúde. Este estudo tem por objetivo contextualizar os benefícios da biomassa de banana verde na saúde humana. A pergunta norteadora para a construção desta revisão integrativa foi: quais os benefícios da biomassa de banana verde para a saúde humana? Para a seleção dos estudos, utilizaram-se as seguintes bases de dados eletrônicas: SCIELO (Scientific Eletronic Library Online), IBECS (Indice Bibliográfico Español de Ciencias de la Salud), LILACS (Literatura LatinoAmericana e do Caribe em Ciências da Saúde) e MEDLINE (Medical Literature Analysis and Retrieval System Online). A estratégia de busca resultou na identificação de 10 artigos, para a confecção deste estudo. Conclui-se que a biomassa de banana verde apresenta benéficos importantes para a saúde humana.

Palavras-chave: Biomassa; Banana verde; Saúde.

\footnotetext{
1 Doutoranda em Engenharia Biomédica/ Instituto de Pesquisa e Desenvolvimento/UNIVAP, Brasil. E-mail: vaniathais02@hotmail.com.

2 Doutorando em Engenharia Biomédica/ Instituto de Pesquisa e Desenvolvimento/UNIVAP, Brasil. E-mail: raigomezz19@hotmail.com.

3 Assistente Social/Faculdade de Ciências e Tecnológica do Maranhão, Brasil. E-mail: assistente.socialmaria23@gmail.com.

4 Mestranda em Engenharia Biomédica/Instituto de Pesquisa e Desenvolvimento/UNIVAP, Brasil. E-mail: laris_machado@hotmail.com.

5 Nutricionista/Faculdade de Ciências e Tecnologia do Maranhão/FACEMA, Brasil. E-mail: wirnamarilia@hotmail.com.

${ }^{6}$ Nutricionista/Faculdade de Ciências e Tecnologia do Maranhão/FACEMA, Brasil. E-mail: edcx@hotmail.com.

7 Doutora em Saúde Pública/Universidade do Vale do Paraíba, Brasil. E-mail: psgenaro@gmail.com.
} 